\title{
Consciência e representação de segunda ordem: de Reinhold via Fichte a Rosenthal
}

\author{
Consciousness and second-order representation: \\ From Reinhold via Fichte to Rosenthal
}

\begin{abstract}
Christian Klotz
Universidade Federal de Goiás (UFG), Goiânia, G0, Brasil
\end{abstract}

\section{Resumo}

Na sua Filosofia Elementar, Reinhold busca fundamentar a filosofia crítica por meio de uma teoria acerca das condições que possibilitam a representação como tal, o que, para Reinhold, significa ao mesmo tempo investigar as condições que são constitutivas da consciência em geral. Nessa base, Reinhold desenvolve uma teoria acerca das espécies particulares da consciência que são necessárias para o conhecimento e que revelam o caráter reflexivo da consciência. A análise dos tipos particulares da consciência proposta por Reinhold essencialmente envolve a concepção de representações de segunda ordem. O objetivo deste artigo é reconstruir a teoria reinholdiana acerca das representações de segunda ordem e colocá-la no contexto de discussões posteriores sobre representações de ordem superior. Para tal, discute-se a transformação da concepção reinholdiana de representações de segunda ordem nas Meditações sobre a Filosofia Elementar 
de Fichte e a teoria da consciência como pensamento de segunda ordem defendida por D. M. Rosenthal. Desse modo, mostrar-se-á que o pensamento pós-kantiano inaugurado por Reinhold deu origem a questionamentos e concepções que estão presentes nos debates atuais da filosofia da mente.

Palavras-chave: Consciência. Representação. Autoconsciência. Mente.

\section{Abstract}

In his Elementary Philosophy, Reinhold intends to found critical philosophy on a theory about the conditions which make representation as such possible. To Reinhold, this means at the same time to investigate the conditions which are constitutive of consciousness in general. On this base, Reinhold develops a theory about the particular species of consciousness which are necessary for knowledge and which reveal the reflective character of consciousness. Reinhold's analysis of these particular types of consciousness essentially involves the notion of second-order representations. This paper aims to reconstruct Reinhold's theory of secondorder representations and to put it into the context of posterior discussions about higherorder representations. For this purpose, the Fichtean transformation of Reinhold's conception of second order representations in his Own Meditations on Elementary Philosophy and the higher-order thought theory of consciousness defended by David M. Rosenthal are discussed. It is shown that post-kantian thinking, initiated by Reinhold, brought forth questions and conceptions that are present in the debates of today's philosophy of mind.

Keywords: Consciousness. Representation. Self-consciousness. Mind.

A Filosofia Elementar de Reinhold inaugurou a fase de apropriação criativa da filosofia crítica de Kant ao apresentar a filosofia kantiana de modo a inovar tanto o entendimento do seu método quanto dos seus conceitos fundamentais ${ }^{1}$. O projeto reinholdiano pode ser

1 Reinhold publicou duas apresentações da sua Filosofia Elementar (1789 e 1790). Além disso, a exposição posterior e mais precisa da sua concepção do princípio fundamental do saber (1791) foi influente nos debates pós-kantianos. Após sua saída de Jena em 1794, Reinhold reformulou várias vezes sua posição, mudanças estas que não serão contempladas aqui. 
entendido como motivado pela observação de que a teoria da Crítica da Razão Pura, ao tratar de intuições, categorias e ideias como tipos diferentes de representações, pressupõe uma concepção da representação que é fundamental para ela sem nela ser explicitada. Por isso, para compreender os pressupostos teóricos da filosofia crítica Reinhold considerou necessário encontrar uma proposição que apresente de modo evidente as atividades envolvidas na representação como tal. Seguindo a noção metodológica de que uma teoria deve ser construída a partir de um princípio supremo, Reinhold até defendeu a ideia mais forte de que tal proposição deve ser o princípio fundamental de uma teoria da faculdade de representação que seja capaz de fundar a filosofia crítica como um todo. Desse modo seria possível apresentar a filosofia crítica como uma teoria fundada num princípio único - no princípio da representação ou da "consciência em geral".

Tal programa tem uma consequência importante: ao tornar o princípio da representação, identificado com o da consciência, o ponto de partida próprio da filosofia crítica, na formulação do princípio Reinhold não atribuiu à autoconsciência um lugar destacado na fundamentação da filosofia crítica, conforme sugerido pelo próprio Kant pela afirmação de que a consciência Eu penso e a unidade sintética envolvida nela é o "ponto mais alto" da filosofia transcendental ${ }^{2}$. Em vez disso, Reinhold tentou explicar a consciência de si dentro da teoria da faculdade de representação, analisando-a como resultado de um exercício particular dessa faculdade, ou seja, de um ato reflexivo de representar que essencialmente envolve representações de segunda ordem. A análise reinholdiana de determinados tipos da consciência através da concepção de representações de segunda ordem, que é uma contribuição original de Reinhold para a teoria da consciência, está em foco neste artigo. O objetivo do artigo é investigá-la de tal modo que se mostre sua relevância para a filosofia atual da mente.

Para tal, num primeiro passo será apresentada a teoria reinholdiana acerca das representações de segunda ordem, tal como

2 Kant (2001), p. 133 (= CRP, B 134). Um dos primeiros críticos do projeto reinholdiano, Immanuel Carl Diez, focalizou esse aspecto da teoria de Reinhold (ver HENRICH, 2004, p. 1408 et seq.). 
desenvolvida por Reinhold em base da sua concepção fundamental da representação ou da "consciência em geral". Na segunda seção do artigo pretende-se mostrar que, na sua discussão crítica da Filosofia Elementar de Reinhold, o jovem Fichte adotou a concepção reinholdiana da representação de segunda ordem, atribuindo a ela ao mesmo tempo um papel mais forte na teoria da consciência do que o permitido pela análise de Reinhold. Num terceiro passo mostrar-se-á que a transformação fichtiana da concepção de representações de ordem superior aproxima essa concepção de posições que têm um papel importante nas discussões contemporâneas sobre a consciência, particularmente da teoria da consciência como pensamento de segunda ordem que é defendida por David M. Rosenthal. Desse modo, evidencia-se a presença das discussões pós-kantianas na atual filosofia da mente.

\section{Consciência e representação de segunda ordem na Filosofia Elementar de Reinhold}

No Ensaio de uma Nova Teoria da Faculdade Humana de Representação de 1789 Reinhold levanta uma questão que ele considera fundamental para a filosofia, mas que ainda não teria sido resolvida: "Em que consiste a consciência em geral?" (1789, p. 323) ${ }^{3}$. Segundo Reinhold, a chave para compreender a natureza da consciência não pode ser outra que o conceito de representação: a consciência é essencialmente representacional. No entanto, para que se possa explicitar a natureza da consciência através do conceito de representação é preciso investigar com mais pormenor a natureza da própria representação. Pois se a representação é identificada com a "mera representação" (blossen Vorstellung), isto é, com um conteúdo dado na receptividade, o conceito de representação é fraco demais para poder explicar o que é a consciência. Mesmo que a mera representação pertença ao "ânimo" (Gemüthe), sendo nessa medida um estado mental dotado de conteúdo, ela por si ainda não possui a característica de ser um estado da consciência (ver 1789, p. 327-329). Para que se

3 A tradução de todas as citações desta e das demais obras de Reinhold que são citadas neste artigo é do autor.

Rev. Filos., Aurora, Curitiba, v. 30, n. 51, p. 621-644, set./dez. 2018 
possa falar em consciência, é preciso que algo seja representado através da (mera) representação ou, como Reinhold formula do ponto de vista da primeira pessoa: que "eu me represento algo" (ich mir etwas vorstelle) $(1789$, p. 328). No entanto, isso exige que a mera representação seja distinguida pelo sujeito de si mesmo e do objeto e referida a ambos, o referir da representação ao objeto estabelecendo a relação representacional com o objeto e o referir da representação ao sujeito sendo a autoatribuição da representação (ver 1789, p. 321 et seq.; 1790, p. 144 et seq. e 168 et seq.). Segundo Reinhold, o duplo distinguir e referir referente à mera representação, atividade esta pela qual representamos algo, é o fato fundamental do qual a filosofia crítica deve partir e que consequentemente deve ser apresentado pelo seu primeiro princípio. Além disso, como consequência da sua crítica à identificação da mera representação com a consciência, Reinhold defende que o "representar-algo" entendido assim é uma condição necessária da consciência: "portanto", ele conclui, "não se pode entender pela consciência em geral nenhuma representação, mas apenas aquela alteração do ânimo pela qual a mera representação é referida ao sujeito e ao objeto"' (1789, p. 324)

No entanto, Reinhold não defende apenas a tese de que o representar é uma condição necessária da consciência, mas também a de que tal ato é uma condição suficiente da consciência. Com isso, a "consciência em geral" (Bewusstseyn überhaupt) é identificada com o representar que é caracterizado pelo duplo distinguir e referir envolvido nele. Com essa tese forte Reinhold exclui que possa haver um representar de objetos que não seja consciência. Segundo Reinhold, que filósofos como Leibniz e Platner supuseram a existência de estados representacionais inconscientes deve-se ao fato de que eles confundiram o representar com a mera representação ou até com estados mentais em geral. Reinhold não nega que pode haver estados inconscientes da mente como condições ou como efeitos dos seus estados representacionais. No entanto, ele insiste que não se pode identificar a mente ou "o

4 Cabe observar que frequentemente Reinhold refere-se ao fato expresso pelo primeiro princípio ao utilizar a substantivização "o representar" (das Vorstellen) em vez do substantivo "representação" (Vorstellung), o que exprime melhor as atividades envolvidas nesse fato do que o substantivo "representação" (Vorstellung), que pode também referir-se à mera representação (ver, por exemplo, 1789, p. 330).

Rev. Filos., Aurora, Curitiba, v. 30, n. 51, p. 621-644, set./dez. 2018 
ânimo" (das Gemüthe) com a consciência. O que torna a mente consciente é justamente a atividade pela qual a mente representa algo $(1789, \mathrm{p}$. 323 e 329; 1790, p. 218 et seq.).

No entanto, a tese errônea de que há representações inconscientes segundo Reinhold pode ter outro motivo do que a concepção demasiadamente fraca da representação que a identifica com estados mentais em geral. Ela pode também surgir como consequência de uma concepção da consciência que é forte demais, a saber, de uma concepção da consciência que identifica a consciência em geral com a consciência "clara" ou "distinta". Pois, Reinhold admite, há "representações sem consciência clara" que se pode caracterizar como "obscuras" (dunkel) $(1789$, p. 331). Se supormos que a consciência é essencialmente clara, fica inevitável considerar inconscientes tais representações. A estratégia de Reinhold na refutação de tal posição é decisiva para a formulação da sua concepção da consciência, cunhando a construção da sua teoria da faculdade de representação. Reinhold objeta à identificação da consciência com a representação clara ou distinta que ela confunde à "consciência em geral" (Bewusstsein überhaupt) com "espécies particulares" (besondere Arten) da consciência. A consciência é sempre e essencialmente um representar de objetos. No entanto, ela não é necessariamente clara ou distinta. Portanto, há uma consciência obscura, e segundo Reinhold uma versão da teoria das representações inconscientes deve-se ao fato de que se confunde tal consciência com a ausência de consciência. Reinhold defende que a consciência obscura é o primeiro degrau do desenvolvimento da consciência, a partir do qual a consciência clara e a distinta podem ser formadas (ver 1789, p. 336).

Com isso, Reinhold vai além da investigação da questão "O que é a consciência em geral?", entrando numa teoria acerca de tipos particulares da consciência. Tal passo exige introduzir um critério da diferenciação dos tipos da consciência. É justamente nesse ponto que Reinhold desenvolve um elemento altamente interessante e original da sua Filosofia Elementar. Pois Reinhold vê a diferença entre a consciência obscura e os tipos superiores da consciência no fato de que as últimas envolvem representações de segunda ordem através das quais a consciência torna objeto de si o que é constitutivo dela mesma. É na 
consciência clara e distinta que Reinhold encontra a reflexividade da qual a consciência é capaz.

Para entender a função de representações de segunda ordem na teoria de Reinhold é importante observar que, segundo Reinhold, a consciência como tal envolve elementos que, embora sejam necessários para a representação de objetos, não são representados no mesmo ato representacional que os contém: a (mera) representação que é distinguida do objeto e referida a ele, e o sujeito do qual a representação é distinguida e ao qual ela é atribuída. Esses elementos estão "na" consciência sempre que um objeto é representado, fazendo parte do seu "conteúdo" (Inhalt), mas não são aquilo do qual se tem consciência no mesmo ato representacional, o que é apenas o objeto ao qual a representação é referida (1789, p. 322 e 325). Tais elementos do conteúdo da consciência que não são seu objeto mas que estão necessariamente envolvidos em qualquer ato representacional podem ser caracterizados como elementos "subjetivos" da consciência. Para que haja uma consciência desses elementos subjetivos, isto é, para que a mera representação como tal e seu sujeito se tornem objetos da representação, é preciso que estes sejam representados por representações de ordem superior - que haja uma "representação da representação" e uma "representação do sujeito que representa" (ver 1789, p. 325 et seq. e 331 et seq.; 1790, p. 161 et seq. e 221 et seq.). Reinhold enfatiza que a existência de representações de segunda ordem não é necessária para a consciência como tal. A identificação da "consciência em geral" com a representação de segunda ordem é um dos motivos por que alguns filósofos privam o representar pré-reflexivo do seu caráter consciente e consequentemente supõem a existência de representações inconscientes. No entanto, Reinhold defende que representações de segunda ordem são necessárias para que a consciência possa se tornar consciente de si mesma e da sua própria relação com objetos. É justamente a essa consciência refletida da própria consciência que, segundo Reinhold, os conceitos de consciência "clara" e "distinta" se referem.

Com base nessa ideia fundamental, Reinhold entende por "consciência clara" (klares Bewusstseyn) a consciência na medida em que nela não se tem consciência apenas do objeto que é representado por uma 
representação de primeira ordem, mas também da representação através da qual o objeto é representado (1789, p. 331; 1790, p. 221). Para que haja tal consciência é necessário que a representação de primeira ordem por sua vez seja representada através de uma representação. Portanto, a consciência clara enquanto consciência de uma representação essencialmente envolve uma "representação da representação", ou seja, uma representação de ordem superior. Cabe ressaltar que a consciência clara entendida assim é uma característica possível de atos representacionais que podem estar direcionados para objetos muito diferentes: a consciência de um objeto externo é clara na medida em que envolve uma consciência da representação através da qual o objeto externo é representado; e a consciência de si é clara se ela envolve a consciência da representação através da qual o "Eu" é representado (ver 1789, p. 332). No entanto, diferentemente da consciência de objetos externos, a autoconsciência pressupõe que já haja alguma consciência clara. Pois segundo Reinhold a autoconsciência também envolve uma representação de ordem superior, a saber, a "representação do sujeito que representa". Reinhold denomina a consciência na medida em que ela envolve a consciência de si como sujeito da representação de "consciência distinta" (deutliches Bewusstseyn) (ver 1789, p. 333; 1790, p. 222). Para que possa haver uma consciência distinta, é preciso que já haja alguma consciência de uma representação como tal (uma consciência "clara"), a consciência distinta sendo a consciência de si como sujeito dessa representação - consciência esta que ainda não está envolvida na consciência da representação como tal enquanto "representação da representação".

Segundo isto, a autoconsciência deve-se a um ato reflexivo no qual o sujeito de um ato de representar torna-se objeto de uma representação de ordem superior. Reinhold enfatiza que é só desse modo - através de uma objetivação de si mesmo - que a consciência de si como sujeito de representações é possível. É verdade que na "representação em geral" a (mera) representação é distinguida do sujeito e referida a este como a "sua". O sujeito da representação faz parte do "conteúdo" do representar, sendo um dos elementos que estão envolvidos nos atos de distinguir e referir que são constitutivos dele. No entanto, isso não significa que sempre haja uma consciência do sujeito da representação. Pois 
só o objeto que é representado num estado representacional é aquilo do qual há consciência nesse estado. Portanto, na medida em que a função de ser sujeito da representação sempre difere da do objeto que é representado, o sujeito de um ato de representar como tal nunca pode ser aquilo do qual se tem consciência nesse ato. Reinhold formula explicitamente essa implicação da sua concepção da consciência: "Aquilo que numa consciência é o mero sujeito dela na mesma consciência não pode ser um objeto da consciência, e consequentemente também não pode ser o objeto da representação; isto é: o sujeito da consciência enquanto mero sujeito da consciência não pode ser representado" (1789, p. 325). Consequentemente, a autoconsciência só é possível na medida em que não só a representação envolvida numa consciência, mas também seu sujeito como tal se tornam objeto de uma representação de segunda ordem. Com isso, Reinhold exclui a possibilidade de uma autoconsciência pré-reflexiva. E ele entende a palavra "eu" que dá expressão à consciência de si como designação de um objeto específico, ou seja, como termo que se refere ao sujeito do representar "na medida em que este é objeto de uma representação" (1789, p. 325).

A análise reinholdiana da autoconsciência como resultado de um ato reflexivo que envolve uma representação de segunda ordem levanta um problema que não passou despercebido a Reinhold. Supor que a consciência de si envolve uma "representação do sujeito que representa" não é suficiente para explicar a autoconsciência. Pois tal consciência essencialmente envolve a consciência da identidade com o sujeito que é representado. Nas palavras de Reinhold:

No entanto, a autoconsciência não contém apenas a representação do sujeito que representa, mas também do sujeito que representa na mesma consciência, isto é, na autoconsciência o objeto da consciência é representado como idêntico com o sujeito. Como tal identidade é possível apesar da diferença entre sujeito e objeto que é essencial para a consciência, na mesma consciência? (1789, p. 335).

Reinhold percebeu então que a teoria das representações de ordem superior não é suficiente para entender como a consciência de si é possível. Ele tentou resolver o problema ao chamar atenção para o suposto fato 
de que a matéria da representação do sujeito que representa são as formas apriorísticas da intuição e do pensamento, motivo este pelo qual o sujeito só pode entender o objeto de tal representação como idêntico consigo mesmo (ver 1789, 335-336). Entretanto, independentemente de se a solução proposta por Reinhold é convincente - ele deu um passo importante ao focalizar explicitamente a consciência de si como um problema da filosofia, iniciando com isso a teoria filosófica da autoconsciência 5 .

Porém, Reinhold não apenas buscou analisar a autoconsciência através da sua teoria das representações de ordem superior. Além disso, ele associou a distinção dos três tipos particulares da consciência (consciência obscura, clara e distinta) com um modelo da formação ontogenética da autoconsciência, segundo o qual a partir de uma consciência primordial e pré-reflexiva de objetos a mente se elevaria para a consciência das representações através das quais ela representa objetos e finalmente para a consciência de si como sujeito que representa. Reinhold acreditava ter encontrado com isso as "linhas fundamentais para a história própria da gênese da importante representação do $E u^{\prime \prime}$ (1789, p. 336) - gênese esta que é essencialmente a ascensão de representações de primeira ordem para um representar reflexivo de segunda ordem.

\section{A concepção fichtiana das representações de segunda ordem nas Meditações Próprias sobre a Filosofia Elementar}

O manuscrito "Meditações Próprias sobre a Filosofia Elementar" (Eigne Meditationen über Elementarphilosophie) é o mais importante documento do processo de surgimento do projeto filosófico de Fichte ${ }^{6}$. Nele, Fichte mantém ainda vários elementos da Filosofia Elementar de Reinhold. No entanto, no decorrer das suas reflexões ele insere esses elementos no contexto de uma fundamentação da filosofia que

Cf. Henrich (1989) e Stolzenberg (1996).

6 Fichte escreveu o manuscrito entre 0 início de novembro de 1793 e meados de janeiro de 1794, o mesmo período em que ele se dedicou à Resenha do Enesidemo (ver GA II/3, p. 19). Cabe observar que nesse manuscrito Fichte ainda não utiliza a denominação “Doutrina da Ciência” (Wissenschaftslehre) para referir-se ao seu próprio projeto filosófico. 
difere muito da proposta de Reinhold. Tal diagnóstico vale também com relação à apropriação fichtiana da concepção das representações de segunda ordem que Reinhold havia introduzido na sua Filosofia Elementar. Nas Meditações Próprias, Fichte utiliza os conceitos reinholdianos de "representação da representação" e "representação do sujeito que representa" no interior de uma fundamentação da filosofia que busca explicar a estrutura da representação a partir da noção do caráter incondicionado do Eu, em vez de partir da representação como fato evidente. No entanto, a concepção do Eu que tal fundamentação da filosofia envolve surge só no decorrer das reflexões fichtianas sobre a Filosofia Elementar. Inicialmente, concordando nesse ponto ainda com Reinhold, Fichte compreende o Eu como objeto da representação, o que impede entendê-lo como fundamento da representação: "A primeira proposição é a do ' $E u^{\prime}$ - mas este não pressupõe o conceito de representação? O Eu é representado" (GA II/3, p. 26). É com tal observação que Fichte inicia a seção intitulada "Sobre a própria Filosofia Elementar" (Zur Elementar Philosophie selbst), e suas primeiras reflexões sobre o Eu nas Meditações Próprias dizem respeito justamente a sua "existência na consciência" assim entendida.

A nova concepção do Eu que posteriormente é introduzida por Fichte envolve os conceitos de "apresentação" (Darstellung) e "intuição intelectual" (intellektuelle Anschauung) - conceitos estes que Fichte utiliza para explicitar o caráter incondicionado do Eu (ver GA II/3, especialmente p. 88-90) ${ }^{7}$. Cabe observar que inicialmente Fichte identifica ainda a apresentação com a representação de si mesmo: "A apresentação consiste no ato de representar seu $E u^{\prime \prime}$, diz Fichte numa das suas reflexões (GA II/3, p. 89). No entanto, finalmente ele distingue claramente a "apresentação" (Darstellung) da "representação" (Vorstellung), a apresentação sendo entendida como um ato de autoconstituição que subjaz a qualquer autorrepresentação (ver GA II/3, especialmente p. 90 e 97). Com isso, Fichte introduz a noção de um ser-para-si pré-representacional do Eu que é anterior a qualquer determinação do Eu

A ideia de que a fundamentação da filosofia deve partir da incondicionalidade do Eu é formulada pela primeira vez nas Meditações Próprias em GA II/3, p. 48. 
através de predicados. Em consequência disto, Fichte defende agora que na sua essência o Eu não pode ser entendido como objeto da representação, atribuindo a ele uma identidade que está além de qualquer multiplicidade ou mudança.

Com base na nova concepção do Eu, Fichte concebe o representar como o ato pelo qual o Eu originariamente se relaciona com algo outro através da dupla atividade de distinguir e referir envolvida nele. Mas, para entender a possibilidade de tal ato segundo Fichte, é preciso levar em consideração o contraste profundo entre o Eu e o objeto ao qual o Eu se refere através da representação. Pois na medida em que na intuição intelectual o Eu é "para se" de modo pré-representacional, ele difere radicalmente de qualquer objeto - motivo este pelo qual Fichte denomina o objeto de "não-Eu". Portanto, a representação envolve uma "síntese" de elementos que diferem nas suas características mais fundamentais a síntese do Eu e do não-Eu —, e a questão fundamental da teoria da representação é como tal síntese é possível. Parece que a (mera) representação no sentido do "elo" que mediatiza esses elementos precisa estar oposta a si mesma para que ela possa ser referida a ambos. No entanto, se fosse assim, a concepção da representação seria contraditória e a representação impossível. Por isso, Fichte supõe que a representação pode ser referida ao Eu e ao não-Eu só na medida em que há uma atividade do Eu pela qual a oposição entre o Eu e o não-Eu fica suspensa sob determinados aspectos. Pois só na medida em que a oposição entre o Eu e o não-Eu é parcialmente reduzida surgem aspectos da igualdade do Eu e do não-Eu que possibilitam que a representação possa ser referida a ambos sem contradição. Segundo Fichte, a tarefa de diminuir a oposição entre o Eu e não-Eu envolve duas tarefas parciais que são caracterizadas por diferentes "direções-de-ajuste": pode-se inserir no não-Eu características do Eu; e, alternativamente, sob determinados aspectos o Eu pode ser igualado ao não-Eu, sendo, nesse sentido, objetivado.

A “adaptação" parcial do não-Eu ao Eu segundo Fichte é efetuada pela concepção do não-Eu como matéria idêntica e permanente cuja causalidade segue leis constantes. Pois com isso insere-se uma característica do Eu na concepção do não-Eu, a saber, a de ser "realidade idêntica" (GA II/3, p. 132). O Eu é o modelo originário da identidade, 
de modo que a produção unificadora da noção de uma identidade no diverso das qualidades sensíveis confere ao não-Eu uma "egoicidade" parcial. Porém, Fichte observa que a igualdade parcial do Eu e do não-Eu estabelecida desse modo ainda não é suficiente para possibilitar que a representação seja referida a ambos. "A representação do não-Eu", observa Fichte, "mesmo que ela envolva a identidade, não pode imediatamente ser referida ao Eu que está inteiramente oposto a ela" (GA II/3, p. 133). Pois na medida em que a matéria permanente é representada como dotada de qualidades transitórias (seus "acidentes"), ela é representada como sujeita a mudanças. Portanto, sob esse aspecto o Eu e o não-Eu permanecem opostos, na medida em que a identidade originária do Eu deve ser entendida como imutabilidade, excluindo qualquer variação: o Eu puro "é o que é, e não é mais Eu assim que se torna algo outro" (GA II/3, p. 133). Logo, ainda não se entende como as representações variáveis que se referem ao não-Eu como matéria que sempre passa por mudanças podem ser referidas ao Eu como as "suas". Isso exige que o Eu atribua a si mesmo identidade num sentido que não signifique mais imutabilidade, mas continuação na mudança, ou seja, na sequência das suas representações. Contudo, com isso o Eu se torna igual ao não-Eu sob um aspecto fundamental que diz respeito ao seu modo de ser sujeito: agora o Eu não é mais o Eu "puro" que difere radicalmente de qualquer objeto pela sua identidade imutável, mas torna-se um Eu representado por si mesmo como um "quase-objeto" sujeito a mudanças. Nesse sentido Fichte pode dizer que o Eu deve representar-se "como não-Eu" (GA II/3, p. 133). Com isso, a representação do Eu como sujeito que representa é estabelecida como uma condição da possibilidade da representação do não-Eu.

Como Reinhold, Fichte considera uma condição da representação do Eu como sujeito que representa que haja uma "representação da representação" (ver GA II/3, p. 135-136). Com isso, Fichte inicia uma abordagem sobre representações de segunda ordem que claramente é inspirada pela teoria de Reinhold. No entanto, a relação entre a representação de segunda ordem e a representação que é representada por ela em Fichte revela-se altamente complexa. A representação da representação não poderia ser produzida se não tivesse a representação que nela 
é representada - a existência da representação primordial, diz Fichte, é a "condição da existência" da representação de segunda ordem. E a dependência da representação de segunda ordem da representação que ela representa vai ainda mais longe. Pela representação de segunda ordem o conteúdo representacional da representação primordial é correpresentado, e consequentemente também as relações espaço-temporais que são representadas nela como aspectos formais do objeto. Todavia, essas relações já estão completamente determinadas pela representação de primeira ordem. Por isso, Fichte conclui que tanto sob o aspecto da sua existência quanto da sua forma, a representação de segunda ordem depende da representação que é representada por ela.

Não obstante sua dependência existencial e formal da representação primordial, a representação de segunda ordem é essencialmente um produto da atividade do Eu. Ao voltar-se para esse aspecto, Fichte introduz sua concepção do "pensar" (Denken): a espontaneidade peculiar do representar de segunda ordem que se deve à atividade do Eu, dependendo ao mesmo tempo da existência e da determinidade de uma representação já dada, é a "espontaneidade do pensar" (GA II/3, p. 137). No entanto, com isso a relação entre a representação de segunda ordem e a representação representada por ela ainda não está suficientemente explicada. Pois para Fichte o representar é essencialmente um "realizar", isto é, um ato pelo qual realidade é transferida para aquilo que é representado. Desse modo, levanta-se a questão de em que sentido se pode dizer que a representação de segunda ordem "realiza" a representação primordial que é representada nela. Independentemente do seu ser-representado pela representação de segunda ordem, a representação primordial já representa um objeto material. Portanto, a realidade do "não-Eu" que ela representa não pressupõe que haja alguma representação de segunda ordem (ver GA II/3, p. 138). Além disso, também a realidade da representação de primeira ordem enquanto fenômeno interno não se deve ao seu ser-pensado, mas apenas à "sensação interna" (GA II/3, p. 138). Sendo assim, a realidade que é transferida à representação primordial pela representação de segunda ordem deve possuir um caráter peculiar pelo qual ela difere tanto da realidade de objetos externos quando da realidade do "interior" que se conhece 
pela sensação interna. Fichte caracteriza essa realidade como "forma da espontaneidade plena" (Form der völligen Spontaneität). A realidade que a representação primordial recebe da representação de segunda ordem é a de um conteúdo que é pensado e, com isso, apropriado pela própria atividade espontânea. Ao ser representada através de uma representação de segunda ordem, diz Fichte, a representação primordial torna-se um "acidente da faculdade espontânea, ou da faculdade de pensar" (GA II/3, p. 139).

A concepção da realidade da representação primordial enquanto apropriada pelo pensamento espontâneo é decisivo para o conceito de consciência que é desenvolvido nas Meditações Próprias. Pois a realidade que é transferida para uma representação pelo fato de que ela é pensada segundo Fichte é exatamente a da consciência ou, como Fichte diz: ao receber a forma da espontaneidade, o conteúdo representacional é "acolhido na consciência" (ins Bewusstseyn aufgenommen) (GA II/3, p. 138-139). Portanto, a consciência é "espontaneidade da espontaneidade" (Spontaneität der Spontaneität), isto é, o pensar espontâneo de um conteúdo representacional que foi produzido espontaneamente (GA II/3, p. 139). Quando ele finalmente caracteriza a espontaneidade da espontaneidade como "o pensar de uma intuição" fica claro que Fichte reformula a tese kantiana de que o conhecimento exige intuição e pensamento como ideia central da sua teoria da consciência ${ }^{8}$. A leitura fichtiana dessa tese envolve o pressuposto de que a intuição como tal já é representação de um objeto para o qual foi transferida à realidade pela imaginação (ver GA II/3, p. 138). Para Fichte, o pensamento pressupõe que já haja representações intuitivas de objetos. Assim sendo, a função do pensamento não consiste em possibilitar a representação de objetos como tal, mas em possibilitar o caráter consciente de uma intuição que já representa objetos. Com isso, Fichte estabelece a tese de que o pensamento enquanto representar de segunda ordem é constitutivo da consciência. A resposta à questão "O que é a consciência" dada por Fichte nas Meditações Próprias

8 Cabe observar que a caracterização kantiana do juízo como "representação de uma representação" já sugere a ideia de que o pensamento pode ser entendido como representar de segunda ordem (KANT, 2001, p. 102 — CRP A 68 = B 93). 
é: a consciência é um representar de segunda ordem de uma representação de objetos que é operado pelo pensamento.

Com isso, a concepção da representação de segunda ordem recebe um papel mais forte na teoria da consciência do que na Filosofia Elementar de Reinhold. Segundo Reinhold, a "representação da representação" caracteriza uma espécie particular da consciência, a saber, a consciência "clara", não sendo constitutivo da consciência em geral. Como vimos acima, Reinhold explicitamente rejeita a definição da consciência como representação da representação. Em contraste com isso, Fichte identifica a consciência como tal com a representação de segunda ordem. Segundo Fichte, uma representação intuitiva que não é acompanhada por uma representação de segunda ordem pode possuir um caráter representacional, mas não pode ser caracterizada como consciência. Dessa forma, diferentemente da posição de Reinhold, a concepção fichtiana da consciência permite a possibilidade da existência de representações inconscientes, no entanto, sem que tal implicação fosse discutida nas Meditações Próprias.

Fichte parece considerar essencial para o pensamento (e consequentemente para a consciência) a capacidade de tornar-se consciente de si como sujeito que pensa (GA II/3, p. 140). Só com a investigação do Eu penso, diz Fichte, a consciência é desenvolvida (GA II/3, p. 140). Por isso, é através de uma "análise do: Eu penso" que Fichte busca completar sua explicação da consciência (GA II/3, p. 133). Evidentemente, um objetivo de tal análise é explicitar a natureza da "apercepção transcendental" de Kant. Pelo menos inicialmente, nas Meditações Próprias Fichte identifica a representação de si como sujeito da representação com a consciência Eu penso. Portanto, a análise fichtiana do Eu penso consiste em entender a apercepção transcendental como uma representação de segunda ordem, inserindo-a numa perspectiva reinholdiana. Assim, Fichte inicia sua abordagem sobre o Eu penso com a observação: "portanto, só resta a questão: como o sujeito que representa pode ser representado, - e somente essa questão leva-nos para nosso fim" (GA II/3, p. 140). E sua investigação acerca do Eu penso resulta na tese de que tal consciência consiste num pensamento de segunda ordem pelo qual o sujeito é pensado sob o aspecto da referência pensante ao 
não-Eu que ele exerce: "O Eu é pensado, na medida em que ele pensa o não-Eu", Fichte resume sua análise do Eu penso, acrescentando que nessa consciência refletida o Eu é entendido como "causa primeira e independente do pensamento" (GA II/3, p. 142-143).

No entanto, a abordagem fichtiana sobre a representação do sujeito que representa nas Meditações Próprias vai além da análise da consciência Eu penso. Tal consciência, diz Fichte, não é o único modo de como o sujeito que representa é representado. A análise da representação do sujeito que representa deve abranger também a representação de si como sujeito que intui: "É inteiramente verdadeiro que o Eu deve ser pensado na sua relação com o não-Eu que é representado. No entanto, levanta-se também a questão: se ele deve ser pensado somente como sujeito que pensa, ou que, em sentido geral, representa, ou que também intui, sendo passivo" (GA II/3, p. 142). Ao dar uma resposta positiva a essa questão, Fichte amplia a "análise do Eu penso" para uma análise do Eu represento que insere a relação intuitivo-perceptual com o objeto no conteúdo da autorrepresentação. Com isso torna-se explícito um aspecto importante da análise da autoconsciência como "representação do sujeito que representa": ela amplia a concepção da autoconsciência para além da teoria do "cogito" ao considerar a totalidade das faculdades envolvidas na representação relevantes para a autoconcepção que a autoconsciência envolve, inclusive as faculdades sensíveis e imaginativas ${ }^{9}$.

Nas Meditações Próprias Fichte fornece apenas uma análise inicial tanto com relação ao Eu penso quanto ao Eu represento. No entanto, o que fica claro aqui é que Fichte - nesse aspecto seguindo a teoria de Reinhold - analisa a autoconsciência como um tipo de representações de segunda ordem que pressupõe a "representação da representação" como primeira forma de tais representações. O novo aspecto na concepção de Fichte é que o ser-representado do Eu é entendido

Fichte refere-se explicitamente a esse aspecto quando ele diz na apresentação da Doutrina da Ciência de 1794/95 que Reinhold "vai consideravelmente mais longe que Descartes" ao formular a proposição repraesentans sum, ergo sum — no entanto, acrescentando que o representar não é a única determinação do nosso ser. Portanto, segundo a posição adotada por Fichte na Grundlage, a concepção reinholdiana da autoconsciência é ainda estreita demais para abranger todo o conteúdo da autoconsciência, particularmente no que diz respeito aos seus aspectos práticos (GA I/2, p. 262-263; FICHTE, 1984, p. 48). 
como objetivação de um Eu que originariamente difere radicalmente de qualquer objeto. Como foi observado acima, segundo Reinhold a palavra "eu" refere-se ao sujeito que representa "na medida em que este é objeto de uma representação" (1789, p. 325). Desse modo, para Reinhold o Eu é essencialmente o sujeito objetivado. A posição diferente de Fichte acerca da natureza do Eu pressupõe a noção do Eu como apresentação ou intuição intelectual pela qual Fichte explicita o caráter incondicionado do Eu. Tal concepção envolve a ideia de um ser-para-si pré-representacional do Eu que subjaz à autoconsciência no sentido da autorrepresentação do sujeito que representa. É só em base desse entendimento do Eu que se torna possível uma concepção da autoconsciência que a compreenda como um ato no qual "o Eu se torna não-Eu", ou seja, como objetivação de um Eu que originariamente é "para si" sem originariamente ser um objeto para si. No entanto, nas Meditações Próprias Fichte deixa em aberto se ele entende o "para si" que está envolvido na intuição intelectual como uma autoconsciência pré-reflexiva, ou se só a autorrepresentação possui a característica de ser consciência de si. Ainda na Grundlage de 1794/95, Fichte vai manter certa ambiguidade com relação à questão de se o "ato-ação" (Tathandlung) que na primeira apresentação da Doutrina da Ciência substitui a "apresentação" e a "intuição intelectual" das Meditações Próprias pode ser entendida como uma autoconsciência pré-reflexiva ou apenas como um fundamento da consciência que por si ainda não possui a característica de ser consciência de $\mathrm{si}^{10}$. Evidentemente a concepção da autoconsciência pré-reflexiva vai além da concepção reinholdiana da autoconsciência como representação de segunda ordem - em tal consciência, o Eu estaria consciente de si sem tornar-se objeto. É só na segunda versão da Doutrina da Ciência, na chamada Doutrina da Ciência nova methodo, que Fichte vai explicitamente adotar tal concepção como fundamento da sua teoria, introduzindo-a através de um argumento que deve ser

10 Enquanto no § 1 da exposição de 1794/95 0 "ato-ação" (Tathandlung) é caracterizado como autoconsciência pura, no § 5 Fichte tende a privar a autoconstituição pré-reflexiva do Eu do seu caráter consciente e a reconhecer só a reflexão como autoconsciência (ver GA I/2, p. 260 e 263 (§ 1) e p. 406 et seq. (§5); FICHTE, 1984, p. 46 e 48 (§ 1) e p. 147 et seq. (§ 5)). 
considerado uma crítica da análise reinholdiana da autoconsciência como representação de segunda ordem ${ }^{11}$.

\section{Reinhold, Fichte e a análise da consciência como pensamento de segunda ordem de Rosenthal}

Reinhold deu um passo importante na teoria da consciência ao introduzir a concepção de representações de segunda ordem para analisar determinados tipos de consciência. No entanto, em Reinhold tal análise possui um papel limitado na teoria da consciência: segundo Reinhold, não a consciência em geral, mas apenas espécies particulares da consciência envolvem representações de segunda ordem a saber, os tipos de consciência nas quais a mente reflexivamente se torna consciente das representações através das quais ela representa objetos e de si mesma como sujeito das representações. Com isso, a concepção de representações de segunda ordem torna-se fundamental principalmente para o entendimento da autoconsciência (no entanto, como o próprio Reinhold percebeu, sem ser suficiente para a explicação da sua possibilidade). Em contraste com isso, a "consciência em geral" segundo Reinhold pode ser identificada com o representar como tal. Assim, Reinhold defende uma explicação da consciência em geral que nega a necessidade de representações de segunda ordem para a consciência como tal, excluindo com isso a possibilidade de representações inconscientes no sentido de atos representacionais que não envolvem nenhuma consciência do objeto que neles é representado. No entanto, conforme mostrado acima, nas Meditações Próprias Fichte atribuiu a representações de segunda ordem um papel mais forte na teoria da consciência ao identificar a consciência com a "espontaneidade

11 Ver GA I/4, p. 275, IV/2, p. 30 e IV/3, p. 346.0 argumento de Fichte envolve a tese de que 0 sujeito da autorrepresentação pode entender o objeto da sua representação como idêntico consigo mesmo somente se ele já dispõe de uma consciência de si como sujeito da representação. Por isso, a explicação reinholdiana da autoconsciência como ato reflexivo que envolve uma representação de segunda ordem seria circular. Como se sabe, D. Henrich caracterizou a tese antirreinholdiana de Fichte de que a concepção da autoconsciência como reflexão não pode explicar a possibilidade da autoconsciência como o "insight originário de Fichte" (ver HENRICH, 1966, especialmente p. 194-195). 
da espontaneidade", isto é, com o pensamento enquanto ato de representar de segunda ordem. Com isso, a concepção de representações de segunda ordem torna-se fundamental para a análise da consciência como tal, o que ao mesmo tempo abre espaço para a possibilidade de representações inconscientes.

A transformação fichtiana da concepção de representações de segunda ordem estabelece uma noção de consciência que possui afinidade com algumas posições que são defendidas da discussão atual sobre a natureza da consciência. Pois a tese de Fichte de que a "representação da representação" é constitutiva da consciência como tal corresponde à ideia norteadora de várias teorias recentes segundo as quais o caráter consciente de estados mentais se explica pela existência de representações de segunda ordem pelas quais estados mentais que representam objetos são representados (ou "vivenciados") como experiências próprias. Duas versões dessa concepção podem ser distinguidas: a posição que identifica a consciência com o sentido interno enquanto faculdade de percepção interna (a chamada "higher order perception theory"12) e a concepção da consciência como pensamento de ordem superior (posição esta que costuma ser chamada de "higher order thought theory", ou "HOT"). A formulação mais influente da segunda foi proposta por David M. Rosenthal ${ }^{13}$. Na medida em que ele não explica a consciência pela concepção de um sentido interno como faculdade de percepção interna, mas pela noção do pensamento como representação espontânea de representações de objetos, Fichte antecipa a versão das teorias da consciência como representação de segunda ordem que explica a consciência pela existência de pensamentos de segunda ordem ${ }^{14}$.

12 Ver ARMSTRONG, 1984 e LYCAN, 1987.

13 Ver especialmente ROSENTHAL, 1986, 1993 e 2005. Algumas versões das teorias da consciência como representação de ordem superior defendem a tese de que estados de consciência representam a si mesmas. A tese da reflexividade dos estados de consciência foi defendida, por exemplo, por KRIEGEL (2006) e VAN GULICK (2004). Fichte não adotou tal tese. 0 motivo disto deve ser que para ele só o Eu pode ser sujeito de representações — consequentemente, nenhum estado mental, mas só o Eu é capaz de representar a si mesmo.

14 Cabe observar que em GA II/3, p. 83 Fichte caracteriza a sensação interna como "representação da representação". Com isso, Fichte defende uma concepção do sentido interno como faculdade de representações de segunda ordem que parece corresponder a teorias atuais da consciência como percepção (interna) de segunda ordem. № entanto, Fichte não explica a consciência pela concepção do sentido interno como faculdade de percepção interna, mas pela concepção do pensamento 
No entanto, Fichte não defende tal concepção pelos mesmos motivos que subjazem às atuais teorias da consciência como pensamento de segunda ordem. Pois seu objetivo é destacar a espontaneidade do pensamento como constitutivo da própria consciência: só na medida em que elas são pensadas e apropriadas ativamente, as representações produzidas pela imaginação podem tornar-se experiências conscientes. Assim, Fichte busca focalizar o pensamento espontâneo do Eu como fundamento do caráter consciente de representações. Tal orientação "egológica" não está presente na teoria atual da consciência como representação de ordem superior. Em vez disso, o objetivo central dessa teoria é explicar a diferença entre representações conscientes e inconscientes, a existência de representações inconscientes sendo considerada um fato evidente. Segundo a explicação oferecida pela teoria da consciência como representação de segunda ordem, representações inconscientes seriam aquelas que não são representadas por representações de ordem superior, possuindo ao mesmo tempo todas as características representacionais que as representações conscientes possuem. Embora a posição de Fichte nas Meditações Próprias deixe espaço para a suposição de que há representações inconscientes, não fica claro aqui em que medida Fichte está disposto a reconhecer a existência de tais representações. Em todo caso, diferentemente das teorias atuais da consciência como representação de segunda ordem, a posição fichtiana não envolve o pressuposto de que há representações inconscientes como elemento constitutivo dela ${ }^{15}$.

Nas discussões atuais da filosofia da mente não é comum referir-se às posições de Reinhold e Fichte. No entanto, como buscou-se mostrar neste artigo, a dinâmica altamente produtiva do pensamento que num período relativamente curto originou a Filosofia Elementar de Reinhold e a Doutrina da Ciência de Fichte levou a questões que têm muita afinidade com as que hoje são discutidas na filosofia da mente. Não obstante a

como representação espontânea de representações de objetos, defendendo com isso uma posição que possui afinidade com a teoria da consciência como pensamento de segunda ordem.

15 A questão acerca das representações inconscientes continua sendo polêmica. J. Searle, por exemplo, defende que a noção do representar (ou, como se prefere dizer hoje: da intencionalidade) está essencialmente ligada ao ponto de vista da primeira pessoa. Segundo Searle, estados intencionais necessariamente são estados pelo menos potencialmente conscientes (1992, p. 151 et seq.). 
grande diferença que há entre seus projetos filosóficos e as intenções do debate de hoje, particularmente com relação à discussão atual acerca da natureza da consciência pode-se falar de uma "presença secreta" de Reinhold e Fichte.

\section{Referências}

ARMSTRONG, D. M. Consciousness and causality. In: ARMSTRONG, D. M.; MALCOLM, N. (Org.). Consciousness and Causality. Oxford: [s.n.], 1984. p. 103-119.

FICHTE, J. G. Gesamtausgabe der Bayerischen Akademie der Wissenschaften. Stuttgart-Bad Cannstatt: Frommann-Holzboog, 1962 et seq. (= GA).

FICHTE, J. G. A Doutrina da Ciência de 1794 e Outros Escritos. Seleção de textos, tradução e notas de Rubens Rodrigues Torres Filho. São Paulo: Abril Cultural, 1984. (Coleção Os Pensadores).

HENRICH, D. Fichtes ursprüngliche Einsicht. In: HENRICH, D.; WAGNER, H. (org.), Subjektivität und Metaphysik. Festschrift für Wolfgang Cramer. Frankfurt am Main: [s.n.], 1966. p. 188-232.

HENRICH, D. Die Anfänge der Theorie des Subjekts. In: HONNETH, A. et al. (Org.). Zwischenbetrachtungen: Im Prozeß der Aufklärung. Frankfurt am Main: [s.n.], 1989. p. 106-170.

HENRICH, D. Grundlegung aus dem Ich: Untersuchungen zur Vorgeschichte des Idealismus. Tübingen-Jena (1790-1794). Frankfurt: Suhrkamp, 2004.

KANT, I. Crítica da Razão Pura. Trad. Santos, M. P.; Morujão, A. F. Lisboa: Fundação Calouste Gulbenkian, 2001.

KRIEGEL, U. The same-order monitoring theory of consciousness. In: KRIEGEL, U.; WILLIFORD, K. (Org.). Self-Representational Approaches to Consciousness. Cambridge: MIT Press, 2006. p. 143-170.

LYCAN, W. G. Consciousness. Cambridge/Mass: MIT Press, 1987. 
REINHOLD, K. L. Versuch einer neuen Theorie des menschlichen Vorstellungsvermögens, Prag e Jena: Widtmann und Mauke, 1789.

REINHOLD, K. L. Beiträge zur Berichtigung bisheriger Missverständnisse der Philosophen: Erster Band das Fundament der Elementarphilosophie betreffend. Jena: Mauke, 1790.

REINHOLD, K. L. Über das Fundament des philosophischen Wissens. Jena: Mauke, 1791. ROSENTHAL, D. M. Two concepts of consciousness. Philosophical Studies, v. 49, p. 329-359, 1986.

ROSENTHAL, D. M. Thinking that one thinks. In: DAVIES, M.; HUMPHREYS, G. W. (org.), Concsciousness. Oxford: Blackwell, 1993. p. 197-223.

ROSENTHAL, D. M. Consciousness and Mind. Oxford: Oxford Press, 2005.

SEARLE, J. The rediscovery of the mind. Cambridge: MIT Press, 1992.

STOLZENBERG, J. Selbstbewusstsein. Ein Problem der Philosophie nach Kant. Reinhold-Hölderlin-Fichte. Revue Internationale de Philosophie, n. 197, p. 461-482, 1996.

VAN GULICK, R. Higher-order global states (HOGS): an alternative higher-order model of consciousness. In: GENNARO, R. J. (Hg.). Higher-Order Theories of Consciousness. Amsterdam: John Benjamins, 2004. p. 67-92.

Recibido: $19 / 08 / 2018$

Received: 08/19/2018

Aprobado: 20/09/2018

Approved: 09/20/2018 
